\title{
FLUX-CORED WIRES PROVIDING DEPOSITED METAL WITH HIGH RESISTANCE TO ADHESION WEAR
}

\author{
V.V. OSIN \\ E.O. Paton Electric Welding Institute, NASU \\ 11 Bozhenko Str., 03680, Kiev, Ukraine. E-mail: office@paton.kiev.ua
}

\begin{abstract}
PWI developed flux-cored wires providing deposited metal with sulphide or graphite inclusions, which have the role of solid lubricant and prevent adhesion wear. Comparative studies of heat- and wear resistance at metal-to-metal friction at room and elevated temperatures showed that PP-Np-20Kh5M3FS(S) flux-cored wire can be recommended for welding parts operating under the conditions of increased mechanical loads and moderate cyclic thermal loads. PP-Np-50Kh9S3G(S) flux-cored wire providing deposited metal with high adhesion wear resistance at room temperature can be successfully used for surfacing parts of heavy-duty friction pairs. Having relatively low cost, but requiring application of complex surfacing technology, PP-Np-150S2Yu flux-cored wire can find limited application in surfacing friction pair parts operating at high mechanical loads in the case, if it is cost-effective. 13 Ref., 4 Tables, 5 Figures.
\end{abstract}

Keywords: arc surfacing, flux-cored wires, adhesion wear, wear resistance, thermal stability

Machines and mechanisms having heavy-duty parts in their design are operating practically in all the national economy industries. These are tools and fixtures for hot and cold working of metals, various rollers, shafts, axles, pulleys, crane wheels, etc.

One of the main causes for these parts failures is adhesion wear (Figure 1) [1]. This kind of wear is characterized by the processes of establishing of bonds (seizure points) between two friction surfaces at molecular level and subsequent mechanical breaking up of these bonds. B.I. Kostetsky [2] proposed differentiating between adhesion wear of first and second kind. Adhesion wear of the first kind is observed at sliding friction and low speeds, temperatures and specific pressures, while adhesion wear of the second kind is found at sliding friction at high speeds, great specific pressures and higher temperatures. Currently available surfacing materials, as a rule, do not provide deposited metal resistant to adhesion wear, and lubricant application remains to be the only method to prevent it.

This work is the generalization of PWI experience on development of flux-cored wires, which provide deposited metal with inclusions, having the role of solid lubricant and preventing adhesion wear [3-6].

Steels alloyed with sulphur, as well as graphitized steels were used as surfacing material prototypes. It is known that in both types of these materials, free inclusions of sulphides or graphite improve machinability and lower the friction coefficient [7-9].

Investigations resulted in development of three flux-cored wires, two of which provided deposited metal with sulphide inclusions (PPNp-20Kh5M3FS(S) and PP-Np-50Kh9S3G(S) wires), and one - with graphite inclusions (PP$\mathrm{Np}-150 \mathrm{~S} 2 \mathrm{Yu}$ wire).

The prototype of PP-Np-20Kh5M3FS(S) flux-cored wire was the known wire PP-Np$25 \mathrm{Kh} 5 \mathrm{FMS}$, which is widely applied for reconditioning and strengthening of tools for hot working [10]. From alloying elements in this wire the main attention was given to molybdenum, which forms $\mathrm{MoS}_{2}$ disulphide. By the data of [11], this disulphide is the most effective as the solid lubricant. It has a layered structure, these layers are quite strong, and can move relative to each other, resulting in improvement of tribotechnical characteristics of friction pairs.

Steel 50Kh9S3G, known under «silchrome» trade name, is applied for manufacturing tools for metal cold working, in particular, for cold deep drawing dies, as well as for heavy-duty parts of some friction pairs. These parts service is characterized by minimum thermal loads at considerable mechanical loads, and they most often fail as a result of adhesion wear of the first kind. Considering that thermal stability of steels of this type is minimal, their application under these conditions is quite justified.

For repair surfacing of cold drawing dies, PWI developed PP-Np-50Kh9S3G flux-cored wire, providing deposited metal of composition similar to base metal [10]. This steel has no molybdenum,
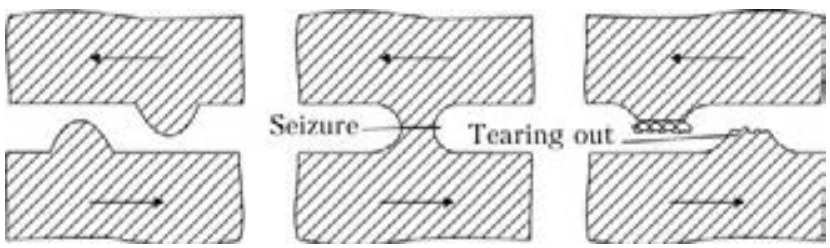

Figure 1. Scheme of adhesion wear of two rubbing metal surfaces 
INTERNATIONAL CONFERENCE «SURFACING»

Table 1. Optimum composition and hardness of metal deposited with PP-Np-20Kh5M3FS(S), PP-Np-50Kh9S3G(S) and PP-Np150S2Yu flux-cored wires

\begin{tabular}{||l|c|c|c|c|c|c|c|c||}
\hline \multirow{2}{*}{ Flux-cored wire grade } & \multicolumn{9}{|c|}{ Element mass fraction, \% } & \multicolumn{2}{c|}{ Hardness } \\
\cline { 2 - 10 } & $\mathrm{C}$ & $\mathrm{Mn}$ & $\mathrm{Si}$ & $\mathrm{Cr}$ & $\mathrm{Mo}$ & $\mathrm{V}$ & Other & HRC \\
\hline PP-Np-20Kh5M3FS(S) & 0.25 & 0.63 & 0.92 & 4.72 & 2.98 & 0.54 & $0.78 \mathrm{~S}$ & $44-46$ \\
\hline PP-Np-50Kh9S3G(S) & 0.64 & 0.55 & 2.65 & 9.25 & - & - & $0.70 \mathrm{~S}$ & $56-58$ \\
\hline PP-Np-150S2Yu & 1.80 & 0.58 & 1.46 & - & - & - & $0.09 \mathrm{Al}$ & $41-44$ \\
& & & & & & & $0.02 \mathrm{Ca}$ & \\
\hline
\end{tabular}

and to avoid increase of flux-cored wire cost, the possibility of producing in the deposited metal sulphide inclusions of other alloying elements, which can improve the tribotechnical properties of deposited metal of this type, was studied [12].

$\mathrm{PP}-\mathrm{Np}-150 \mathrm{~S} 2 \mathrm{Yu}$ flux-cored wire provides deposited metal of graphitized steel type. Application of such materials is one of the methods of improving the tribotechnical characteristics of friction pair parts, graphite inclusions having the solid lubricant role. The main problem here is providing an optimum quantity of globular graphite inclusions without high-temperature heat treatment [6].

Table 1 gives the composition and hardness of metal deposited with PP-Np-20Kh5M3FS(S), PP-Np-50Kh9S3G(S) and PP-Np-150S2Yu fluxcored wires.

Deposited metal composition and wire charge composition, respectively, were selected in keeping with earlier research findings [4-6].

These investigations showed that to provide the required properties of $20 \mathrm{Kh} 5 \mathrm{M} 3 \mathrm{FS}(\mathrm{S})$ and 50Kh9S3G(S) deposited metal, the volume content of complex sulphides of the main alloying elements should be equal to $1.5-2.0 \%$, while their dimensions should not exceed $0.02 \mathrm{~mm}(\mathrm{Fi}-$ gure $2, a, b)$. To satisfy these conditions, sulphur content in the deposited metal should be equal to $0.5-0.8 \%$, and the total content of the main alloying elements (molybdenum, chromium, vanadium, manganese) should be 8 to $10 \%$ [4, 5].

Volume content of graphite inclusions (1.0$1.3 \%$ ) in the deposited metal structure, which provides minimum wear of deposited metal of the type of graphitized steel $150 \mathrm{~S} 2 \mathrm{Yu}$ was also experimentally determined. To produce such a quantity of graphite inclusions, the deposited metal should contain, \%: 1.35-1.50 C, 1.5$2.0 \mathrm{Si}, 0.1-0.2 \mathrm{Al}$ and $0.02-0.05 \mathrm{Ca}$, and surfacing should be conducted with preheating up to $400{ }^{\circ} \mathrm{C}$ and tempering immediately after surfacing at the same temperature [6]. It should noted that this is exactly the preheating temperature that is required to avoid cracking in high-carbon deposited metal 150S2Yu. Figure 2, $c$ gives the structure of deposited metal of this type.

Comparative evaluation of wear resistance of deposited metal of this type at sliding friction of metal on metal without lubrication at room temperature, was conducted in friction machine, described in [13]. Testing was performed by crater wear method by «shaft-plane» scheme without any additional lubricant feeding into friction zone. Samples cut out of deposited metal upper layers for tribotechnical testing had the dimensions of $3 \times 17 \times 20 \mathrm{~mm}$. Wearing proceeded over $3 \times 20 \mathrm{~mm}$ plane. The counterbody of $40 \mathrm{~mm}$ diameter and $12 \mathrm{~mm}$ height was made from quenched steel 45 of hardness HRC 42.

At sample testing, deposited metal wear was determined by worn crater volume. Volume of worn crater on the surfaced sample was calculated by known formulas by average width of worn crater, using toolmaker's microscope with not more than $0.01 \mathrm{~mm}$ error. Total error of sample wear determination did not exceed $1 \%$. Counterbody wear was determined by its mass loss with not more than $0.0001 \mathrm{~g}$ error.

Proceeding from the results of earlier research, the following test mode was selected: slip velocity of $1 \mathrm{~m} / \mathrm{s}$, load of $30 \mathrm{~N}$, test duration of $600 \mathrm{~s}$,
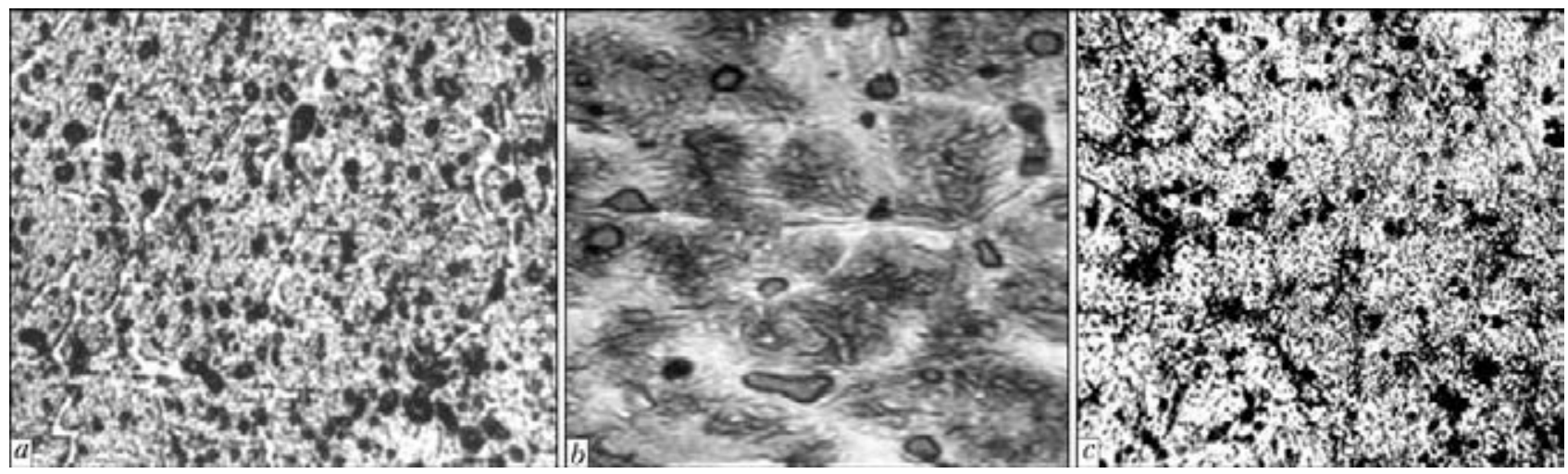

Figure 2. Microstructure of 20Kh5M3FS $(a), 50 \operatorname{Kh} 9 \mathrm{~S} 3 \mathrm{G}(\mathrm{S})(b)$ and $150 \mathrm{~S} 2 \mathrm{Yu}(c)$ deposited metal $(a, c-\times 500 ; b-$ $\times 1000)$ 
Table 2. Wear resistance of metal deposited by PP-Np20Kh5M3FS(S), PP-Np-50Kh9S3G(S) and PP-Np-150S2Yu fluxcored wires at room temperature

\begin{tabular}{||l|c|c||}
\hline \multicolumn{1}{|c|}{ Deposited metal } & $\begin{array}{c}\text { Sample wear, } \\
\mathrm{mm}^{2} / \mathrm{m}\end{array}$ & $\begin{array}{c}\text { Counterbody wear, } \\
\mathrm{g} / \mathrm{m}\end{array}$ \\
\hline 20Kh5M3FS(S) & 0.0017 & 0.0046 \\
\hline 50Kh9S3G(S) & 0.0026 & 0.0035 \\
\hline 150S2Yu & 0.0020 & 0.0031 \\
\hline Steel 45 (reference) & 0.0076 & 0.0037 \\
\hline
\end{tabular}

which ensured stabilization of tribotechnical characteristics of all the studied samples. Application of positioning system allowed testing of each sample to be repeated not less than 3 times on a new section of sample friction surface and on a new friction groove of the same counterbody.

Table 2 gives the results of wear resistance evaluation for three types of deposited metal and reference sample from quenched steel 45 by the same procedure. Data on wear of counterbody from quenched steel 45 are also given there.

As can be seen from the given data, the studied types of deposited metal can be arranged as follows by wear resistance level (in descending order): 20Kh5M3FS(S), 150S2Yu, 50Kh9S3G(S). Counterbody wear resistance changes as follows (depending on contacting sample): 150S2Yu, 50Kh9S3G(S), 20Kh5M3FS(S).

Investigation of wear resistance of metal deposited with PP-Np-20Kh5M3FS(S) and PP-Np150S2Yu flux-cored wires at metal-on-metal friction at higher temperatures was performed for the case of tools for hot working of metals and alloys. As was noted above, testing of samples surfaced with PP-Np-50Kh9S3G(S) wire by this procedure was not performed, as this wire is not designed for surfacing parts, exposed to high temperatures in service. Investigations were performed by «shaft-plane» scheme without additional feeding of lubricant into the friction zone. Surfaced blanks were used to prepare samples of $40 \times 10 \times 17 \mathrm{~mm}$ dimensions with $10 \times 40 \mathrm{~mm}$ size of friction plane. Deposited layer thickness was equal to $8-10 \mathrm{~mm}$.

Abrading ring was heated by gas-oxygen flame. Owing to precisely determined flow rate of natural gas and oxygen, abrading ring-counterbody temperature was maintained at a constant level of 950 to $980{ }^{\circ} \mathrm{C}$, that was periodically controlled by optical pyrometer.

Wear testing at metal-on-metal friction at higher temperatures was conducted for $1 \mathrm{~h}$ at $17.5 \mathrm{~kg}$ load; speed of ring-counterbody revolution was $30 \mathrm{rpm} ; 120 \mathrm{~mm}$ diameter rings from quenched steel 45 were used as counterbodies. Tested sample surface temperature in the abrasion zone was equal to about $600{ }^{\circ} \mathrm{C}$. During testing, the sample makes reciprocal motions in the vertical plane: $20 \mathrm{~mm}$ oscillation amplitude, $62 \mathrm{~min}^{-1}$ oscillation frequency (Figure 3) [13]. Reference samples were those deposited with PP-

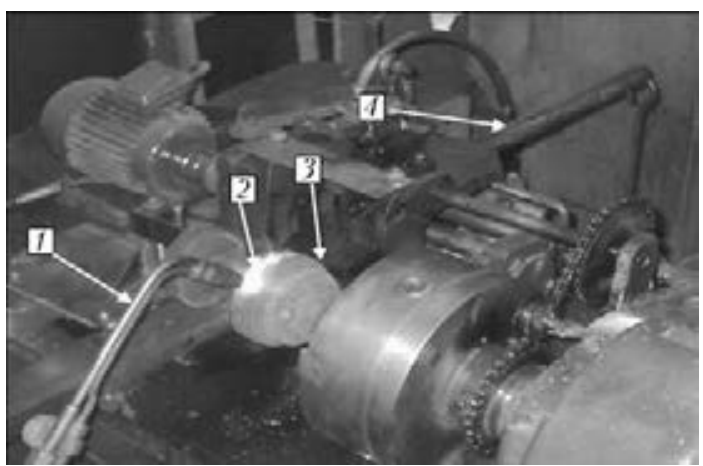

Figure 3. Testing of wear resistance of surfaced samples at higher temperatures: 1 - gas cutter for heating the abrading ring-counterbody; 2 - abrading ring-counterbody; 3 tested sample; 4 - lever for suspending the load

Np-25Kh5MFS flux-cored wire. Test results (averaged over three samples) are given in Table 3.

Sulphur addition to 25Kh5MFS deposited metal practically did not affect the surfaced sample wear, but considerably reduced counterbody wear. Wear of samples surfaced with PP-Np-150S2Yu wire was greater. Wear of ring-counterbodies tested in a pair with these samples was also high.

Analysis of worn surfaces of samples of 20Kh5M3FS(S) deposited metal with 0.02 ( Figure $4, a$ ) and $0.78 \% \mathrm{~S}$ (Figure $4, b$ ) content shows that the sulphides prevent adhesion wear and the worn surface of samples is smoother without seizure traces.

Thermal stability is one of the most important indices for materials, designed for reconditioning and strengthening of tools for hot working of metals. Testing of surfaced sample thermal stability was conducted by the following procedure: sample dimensions of $30 \times 40 \times 40 \mathrm{~mm}$, heating of deposited polished sample surface by gas cutter up to $800{ }^{\circ} \mathrm{C}$ (heated spot of $15 \mathrm{~mm}$, sample surface of $40 \times 40 \mathrm{~mm}$ size is heated), heated surface cooling by water jet to $60{ }^{\circ} \mathrm{C}$. Coolingheating cycles were repeated up to appearance of crazing visible to a naked eye (Figure 5). Thermal stability evaluation was conducted by the number of heating-cooling cycles up to appearance of the first cracks and reaching a certain degree of cracking - appearance of crazing.

Thermal stability testing of samples surfaced with PP-Np-20Kh5M3FS(S) and PP-Np150S2Yu flux-cored wires was performed. Tested as reference samples were those surfaced by standard PP-Np-25Kh5MFS flux-cored wire.

Table 3. Wear resistance of metal deposited by PP-Np20Kh5M3FS(S), PP-Np-150S2Yu and PP-Np-25Kh5FMS fluxcored wires at higher temperatures

\begin{tabular}{||l|c|c||}
\hline \multicolumn{1}{|c|}{ Deposited metal } & $\begin{array}{c}\text { Sample wear, } \\
\mathrm{kg} / \mathrm{m} \cdot 10^{-4}\end{array}$ & $\begin{array}{c}\text { Counterbody } \\
\text { wear, } \mathrm{kg} / \mathrm{m} \cdot 10^{-4}\end{array}$ \\
\hline 20Kh5M3FS(S) & 27.31 & 26.24 \\
\hline 150S2Yu & 31.60 & 59.48 \\
\hline 25Kh5FMS (reference) & 26.23 & 70.24 \\
\hline
\end{tabular}




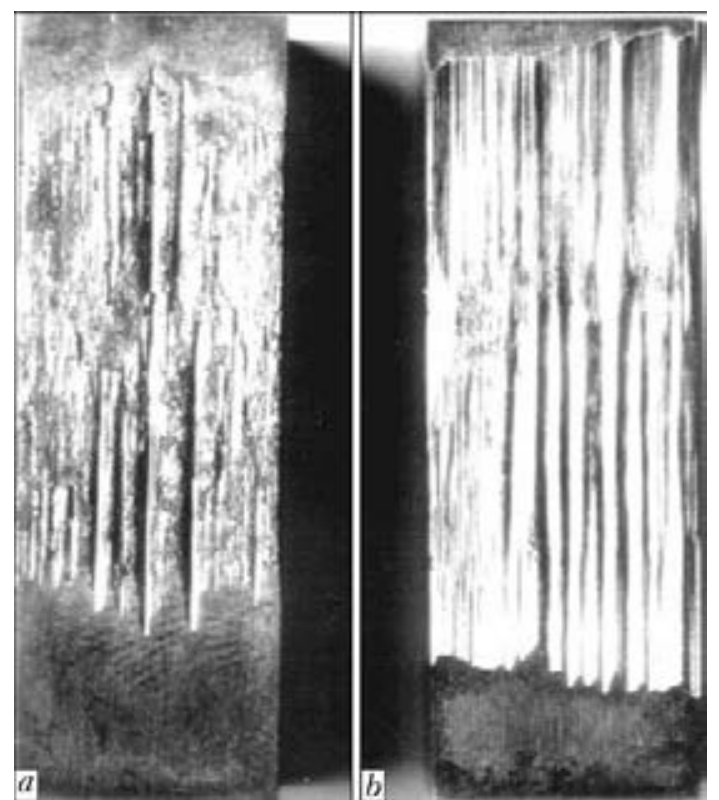

Figure 4. Worn surface of samples of 20Kh5M3FS(S) deposited metal with $0.02(a)$ and $0.76(b) \% \mathrm{~S}$

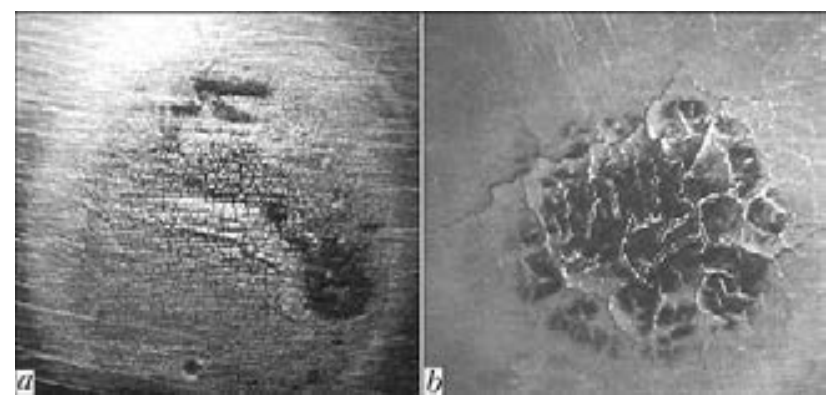

Figure 5. Sample surface after thermal stability testing: $a-20 \operatorname{Kh} 5 \mathrm{M} 3 \mathrm{FS}(\mathrm{S}) ; b-150 \mathrm{~S} 2 \mathrm{Yu}$ deposit

Test results (averaged over three to five samples of each type) are given in Table 4.

Sulphur lowered the thermal stability of deposited metal of 25Kh5MFS type, although its level was still quite high. By this index, 20Kh5M3FS(S) deposited metal alloyed by sulphur, is not inferior to metal deposited by known PP-Np-35V9Kh3FS flux-cored wire [10].

Thermal stability of 150S2Yu deposited metal is not sufficiently high, as the first thermal fatigue cracks appear in the deposited metal already after the first heating-cooling cycles. Here the depth of crazing cracks reached $1.5 \mathrm{~mm}$, whereas in the deposited metal of 20Kh5M3FS(S) type crazing crack depth did not exceed $0.5 \mathrm{~mm}$.

Thus, comparative studies of wear resistance and thermal stability of metal, deposited with flux-cored wires developed at PWI, confirmed that sulphide or graphite inclusions can have the role of solid lubricant and prevent adhesion wear.
Table 4. Thermal stability of samples surfaced by PP-Np20Kh5M3FS(S), PP-Np-150S2Yu and PP-Np-25Kh5FMS fluxcored wires

\begin{tabular}{||l|c|c||}
\hline \multirow{2}{*}{\multicolumn{1}{|c|}{ Deposited metal }} & \multicolumn{2}{|c|}{ Thermal stability, cycle number } \\
\cline { 2 - 3 } & $\begin{array}{c}\text { Appearance of } \\
\text { first cracks }\end{array}$ & $\begin{array}{c}\text { Appearance of } \\
\text { crazing }\end{array}$ \\
\hline 20Kh5M3FS(S) & 25 & 125 \\
\hline 150S2Yu & 4 & 100 \\
\hline 25Kh5MFS (reference) & 67 & 180 \\
\hline
\end{tabular}

Based on these studies, PP-Np-20Kh5M3FS(S) wire can be recommended for surfacing parts, exposed to increased mechanical loads and moderate cyclic thermal loads in service. PP-Np50Kh9S3G(S) wire providing deposited metal with higher adhesion wear resistance at room temperature can be successfully applied for surfacing parts of heavy-duty friction pairs. Having relatively low cost, but requiring complex surfacing technology, PP-Np-150S2Yu wire can find limited application in surfacing of friction pair parts operating at increased mechanical loads, provided it is cost-effective.

1. Ryabtsev, I.A., Senchenkov, I.K. (2013) Theory and practice of surfacing works. Kiev: Ekotekhnologiya.

2. Kostetsky, B.I. (1975) Reliability and life of machines. Kiev: Tekhnika.

3. Osin, V.V., Ryabtsev, I.A. (2004) Effect of sulphur on properties of iron-base alloys and prospects of its application in surfacing materials. The Paton Welding $J ., 10,18-21$

4. Osin, V.V., Ryabtsev, I.A., Kondratiev, I.A. (2006) Study of sulfur effect on properties of deposited metal of Kh5MFS type. Ibid., 12, 12-15.

5. Kondratiev, I.A., Ryabtsev, I.A., Bogajchuk, I.L. et al. (2008) Structure of deposited metal of the type of graphitized hypereutectoid steels. Ibid., 7, 15-18.

6. Ryabtsev, I.A., Kondratiev, I.A., Osin, V.V. et al (2011) Wear- and heat resistance of deposited metal of graphitized steel type. Ibid., 8, 33-36.

7. Goudremont, E. (1959) Special steels. Vol. 1, 2. Moscow: GNTI.

8. Khimushin, F.F. (1963) Stainless steels. Moscow: Metallurgizdat.

9. Zubkova, E.N. (2002) Sulfur effect on structure and properties of deposited high-speed steel. Metallovedenie $i$ Termich. Obrab. Metallov, 9, 27-30.

10. Ryabtsev, I.A., Kondratiev, I.A. (1999) Mechanized electric arc surfacing of metallurgical equipment parts: Refer. book. Kiev: Ekotekhnologiya.

11. Samsonov, G.V., Barsegyan, Sh.E., Tkachenko Yu.G. (1973) On mechanism of lubricating action of sulfides and selenides of refractory metals. Fiz.Khimich. Mekhanika Materialov, 9(1), 58-61.

12. Osin, V.V. (2014) Tribotechnical properties of deposited metal of 50Kh9S3G type with increased sulphur content. The Paton Welding J., 12, 8-10.

13. Rvabtsev, I.I., Chernyak, Ya.P., Osin, V.V. (2004) Block-modular unit for testing of deposited metal. Svarshchik, 1, 18-20. 